\title{
Correction to: Journal of Medicinal Food 2014;17:855-861
}

T THE AUGUST 2014 issue of Journal of Medicinal Food (volume 17, number 8, pp. 855-861), the article entitled "Delphinidin Suppresses PMA-Induced MMP-9 Expression by Blocking the NF- $\kappa$ B Activation Through MAPK Signaling Pathways in MCF-7 Human Breast Carcinoma Cells" by Im et al. requires correction.

In the course of checking the data published in the article, the authors found that Figure 3 was incorrect. The correct Figure 3 and its legend are shown below. The online version of the article has been corrected. All authors would like to apologize for any inconvenience caused.

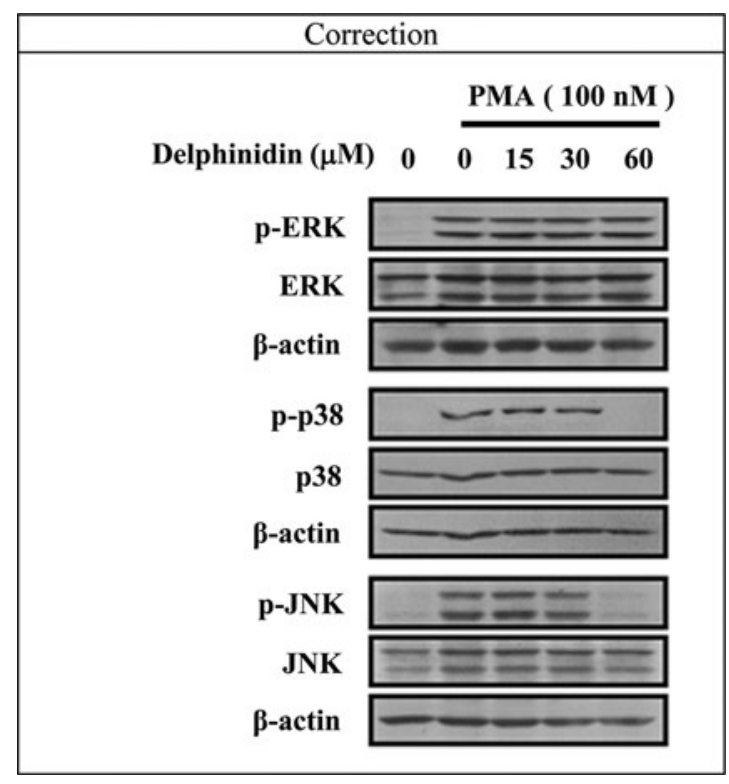

FIG. 3. Effects of delphinidin on PMA-induced activation of MAPK signaling pathways in MCF-7 cells. Cells were treated with PMA (100nM) for $15 \mathrm{~min}$ in the presence of delphinidin, and the phosphorylation levels of ERK1/2, p38 MAPK, and JNK were measured by Western blotting. The results are representative of three independent experiments. 